This is the peer reviewed version of the following article: Hedayatian, M., Liaghat, G.H., Rahimi, Gh, Pol, M.H., Hadavinia, H. and Zamani, R. (2015) Investigation of the high velocity impact behavior of grid cylindrical composite structures. Polymer Composites, which has been published in final form at http://dx.doi.org/10.1002/pc.23853. This article may be used for noncommercial purposes in accordance with Wiley Terms and Conditions for SelfArchiving. 


\title{
Investigation of the high velocity impact behavior of grid cylindrical composite structures
}

\author{
M. Hedayatian ${ }^{\mathrm{a}}$, GH. Liaghat ${ }^{* \mathrm{~b}}$, GH. Rahimi ${ }^{\mathrm{c}}$, M. H. Pol ${ }^{\mathrm{d}}$, H. Hadavinia ${ }^{\mathrm{e}}$, R. Zamanif \\ In Polymer Composites; DOI:10.1002/pc.23853, Available online at: \\ URL: http://onlinelibrary.wiley.com/doi/10.1002/pc.23853/abstract
}

${ }^{a}$ Mechanical Eng. Dept., Tarbiat Moddares University, Tehran, Iran, m.hedayatian@ modares.ac.ir

${ }^{\mathrm{b}}$ Mechanical Eng. Dept., Tarbiat Moddares University, Tehran, Iran, ghlia530@modares.ac.ir

${ }^{c}$ Mechanical Eng. Dept., Tarbiat Moddares University, Tehran, Iran, rahimi_gh@modares.ac.ir

${ }^{\mathrm{d}}$ Mechanical Eng. Dept., Tafresh University, Tehran, Iran, $\underline{\text { M } \mathrm{h} \_ \text {pol@tafreshu.ac.ir }}$

${ }^{\text {e}}$ School of Mech. \& Auto. Engineering, Kingston University London, UK, h.hadavinia@kingston.ac.uk

${ }^{\mathrm{f}}$ Mechanical Eng. Dept., Tarbiat Moddares University, Tehran, Iran, reza.zamani@modares.ac.ir 


\begin{abstract}
In this paper, the experimental behavior of grid cylindrical composite structures, which are used widely in engineering structures, under ballistic impact is investigated. For this purpose some grid cylindrical composite specimens were manufactured by the filament winding process and perforated by projectile using the ballistic gas gun. Incident impact velocity and exit velocities of projectile were recorded in each test. The results show that presence of the ribs prevents pervading of damaged area of one cell to its adjacent cells. The structure behaves differently against projectile with velocity near ballistic limit and higher velocities. The results demonstrated that, by getting close to the ribs location, ballistic limit velocity was increased. However, due to reduction in energy absorption mechanisms in grid composite structures which are impacted in higher velocity than ballistic limit, projectile was exited of grid samples at higher velocity than unstiffened composite shells. Also, investigation of delamination in composite shell and ribs, debonding between ribs and shell (or separation of ribs and shell), residual velocity of projectile, damaged area of the grid specimens and the effects of curvature in two different velocities are presented and the results are discussed.
\end{abstract}

\title{
KEYWORDS:
}

High velocity impact; Grid composite; Damaged area; Ribs; Deviation angle 


\section{Introduction}

High specific stiffness, light weight, easy inspection and being repairable are just some of the advantages of grid composite structures which recently have been led to a huge increase in the use of these structures in aerospace, airplanes, ship buildings, and automotive applications. Furthermore, the use of various stringers and rings on composite cylindrical shells and their effect on behavior of these structures has been studied [1-3]

In fact these structures have the capabilities of simple composite structures and reinforcement composite structures simultaneously [4, 5]. Fiber buckling and fiber breakage, matrix cracking and fracture, shear damage modes, delamination [6, 7], debonding between ribs and skin, large deformation and perforation, plastic deflections and a combination of these damage mechanisms, are possible damage mechanisms which could happens to these structures during different loading situations.

Grid composite structures are susceptible to impact loading by foreign objects during their service life. Generally laminated composites are very sensitive to damages and their behavior in the presence of damages should be properly understood. So, investigating their behavior under impact loading is an important issue. Due to the simultaneous occurrences

of different damage phenomena, dynamic behavior of laminated composite is very complicated. In addition to the damage mechanisms which were discussed, the fracture 
mechanisms can be affected by the shape, velocity of projectile, the angle of collision between projectiles axis and the normal axis of target and even composite layup sequence $[8]$.

During the recent years there are many researchers who have made their efforts to analyze dynamic response of composites under impact loading experimentally and numerically [921].

Cantwell and Morton [22], proved that in the impact of thin CFRP laminates, initial damages occur in the lower layers (layers of the opposite side of projectile) whereas in thick samples damages occur in the upper layers and damage mechanisms are effected by changing velocity and shape of projectile. Damage characteristics and failure strength in different fabric structures with various thickness of the laminates at low velocity impact was carried out by Shyr and Pan [23]. They showed that the layer numbers is one of the important parameters for the energy absorbing mechanisms in composite laminates.

Behavior of single and multiple laminated panels subjected to ballistic impact was investigated experimentally and numerically by Sheikh et al. [24]. In their work, the incidental and residual velocity of the projectile was measured to estimate the energy absorption in the impact test. Karakuza et al. [25]. studied the effects of the equal mass, the equal velocity and the equal energy on the impact behavior of the glass/epoxy composites. They showed that the delamination area in the sample which is subjected to a lower projectile mass with higher incident velocity is lower than the delamination area in the 
sample that is subjected to a higher projectile mass with lower incident velocity for the same impact energy.

Also some researchers have worked on grid cylindrical composite structures and most of their works are related to investigating the resistance of these structures against buckling. For example, buckling load analysis of grid stiffened composite cylindrical shell which had specific cellular shape was done by S. Kidane [26]. Yazdani and Rahimi [27] experimentally investigated the buckling resistance of composite stiffened cylindrical shells under axial loads. In this study they used samples with the same material properties but different profile of stiffeners. Also, the effect of stiffener profile on buckling strength in composite isogrid stiffened shell under axial loading was carried out by Rahimi et al. [28].

Up to now some researchers have investigated the effects of ribs on buckling and twisting loadings but there is no published research in the literatures related to the impact performance of these structures. This study presents the effects of ribs on residual velocity of projectile and the extent of damaged area when the position of collision is changing. Also discussions on experimentally observation of separation of ribs and shell, delamination in ribs and shell and the effects of curvature are presented.

\section{Experiment}

\subsection{Fabrication procedure}

All the specimens were fabricated using E-glass fiber with a specific ratio of resin (CY219) and hardener (HY5161) both supplied by HUNTSMAN Company. Grid cylindrical composite structures produced with a specially designed filament winding machine shown 
in Figure 1. For manufacturing shells the linear and angular speeds were set on $45 \mathrm{~m} / \mathrm{s}$ and $20 \mathrm{rpm}$ and for ribs were set on $5.2 \mathrm{~m} / \mathrm{s}$ and $41 \mathrm{rpm}$.

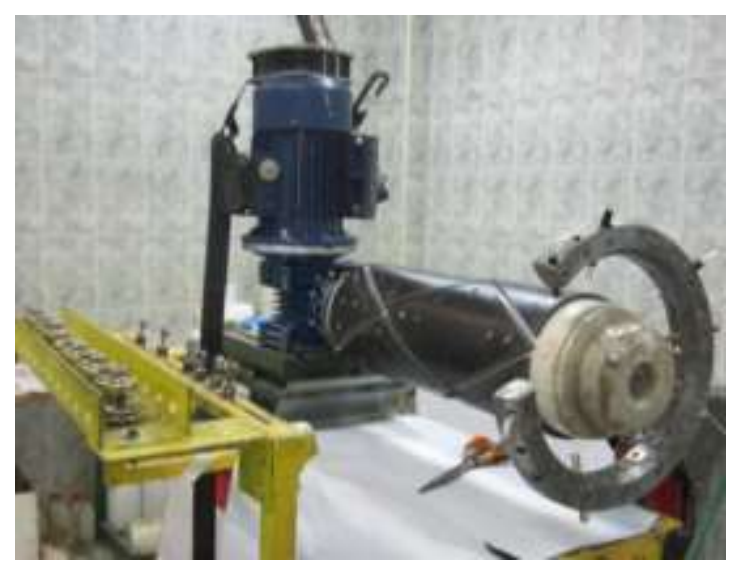

Figure 1: Filament winding machine.

The cylindrical shells have an external diameter of $140 \mathrm{~mm}$ and an overall length of 360 $\mathrm{mm}$. Average mass of a stiffened sample is $530 \mathrm{~g}$ and the thickness of the shell is about 2.4 $\mathrm{mm}$. the shells were supposed to have 15 layers. Three clockwise with 30 degrees angle and three counter-clockwise helical ribs with -30 degrees angle with respect to longitudinal axis of cylinder with square cross section of dimension $6 \times 6 \mathrm{~mm}^{2}$ were used in each specimen. The fibers within the ribs were supposed to be unidirectional and along the length of the ribs. Ribs and shell were fabricated completely integrated. The volume fraction of fillers in shell is 28.44 percent in weigh and 30 percent in weigh in ribs.

Table 1 summarizes geometrical dimensions of specimens. In total, 17 specimens were fabricated for ballistic impact tests.

Table1: Geometrical characteristic of cylindrical shells specimens.

\begin{tabular}{ccc}
\hline & Cylindrical shell & \\
\hline Length & thickness & External Diameter \\
\hline $360 \mathrm{~mm}$ & $2.4 \mathrm{~mm}$ & $140 \mathrm{~mm}$ \\
\hline
\end{tabular}




\begin{tabular}{cc}
\hline & Ribs \\
\hline Length & Cross section \\
\hline $360 \mathrm{~mm}$ & $6 \mathrm{~mm} \times 6 \mathrm{~mm}$ \\
\hline
\end{tabular}

\subsection{Test}

The impact tests were performed using gas gun (Figure 2) at two different impact velocities, $139 \mathrm{~m} / \mathrm{s}$ (the velocity which is higher than ballistic limit of the structure) and $104 \mathrm{~m} / \mathrm{s}$ (the velocity which is near ballistic limit). In all tests, a projectile with a flat nose of $10 \mathrm{~mm}$ in diameter and $8.9 \mathrm{~g}$ in mass was used and because no deformation seen after doing tests, could be considered as rigid bodies.
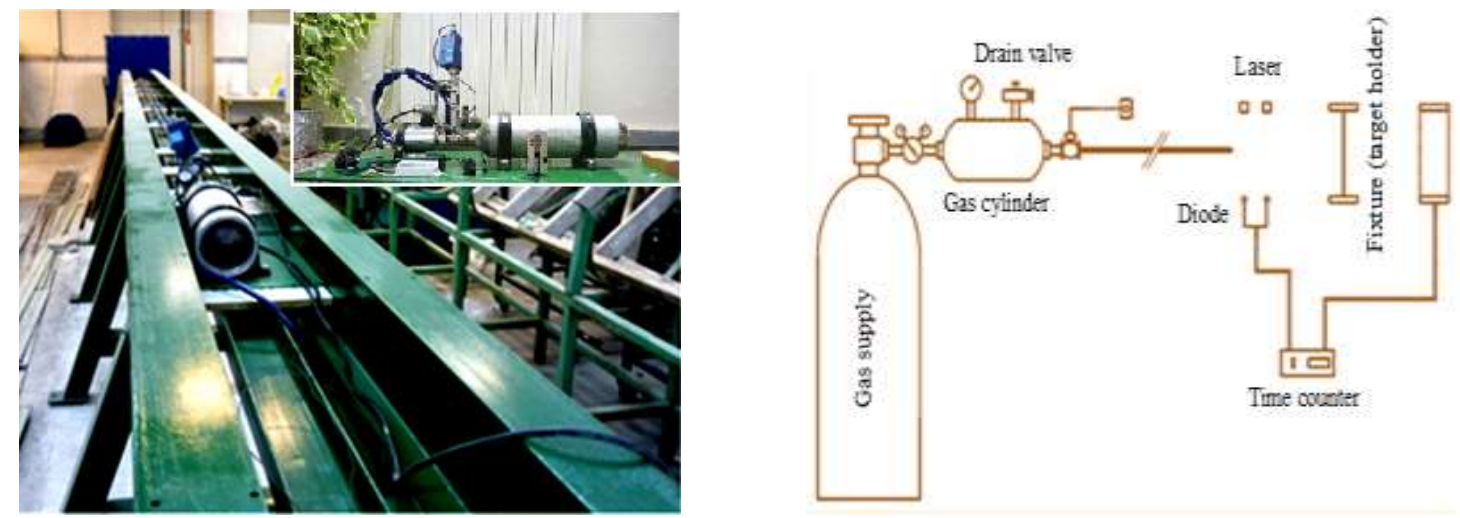

Figure 2: Gas gun.

For measuring residual velocity of projectile, based on symmetry of layers and ribs, each specimen was divided down the middle to perfectly symmetrical halves (Figure 3) and in each test the incident impact velocity and exit velocity of projectile by using laser light sources and light sensitive diode were measured.

The results of tests were asserted by repeating each test at least 3 times. 

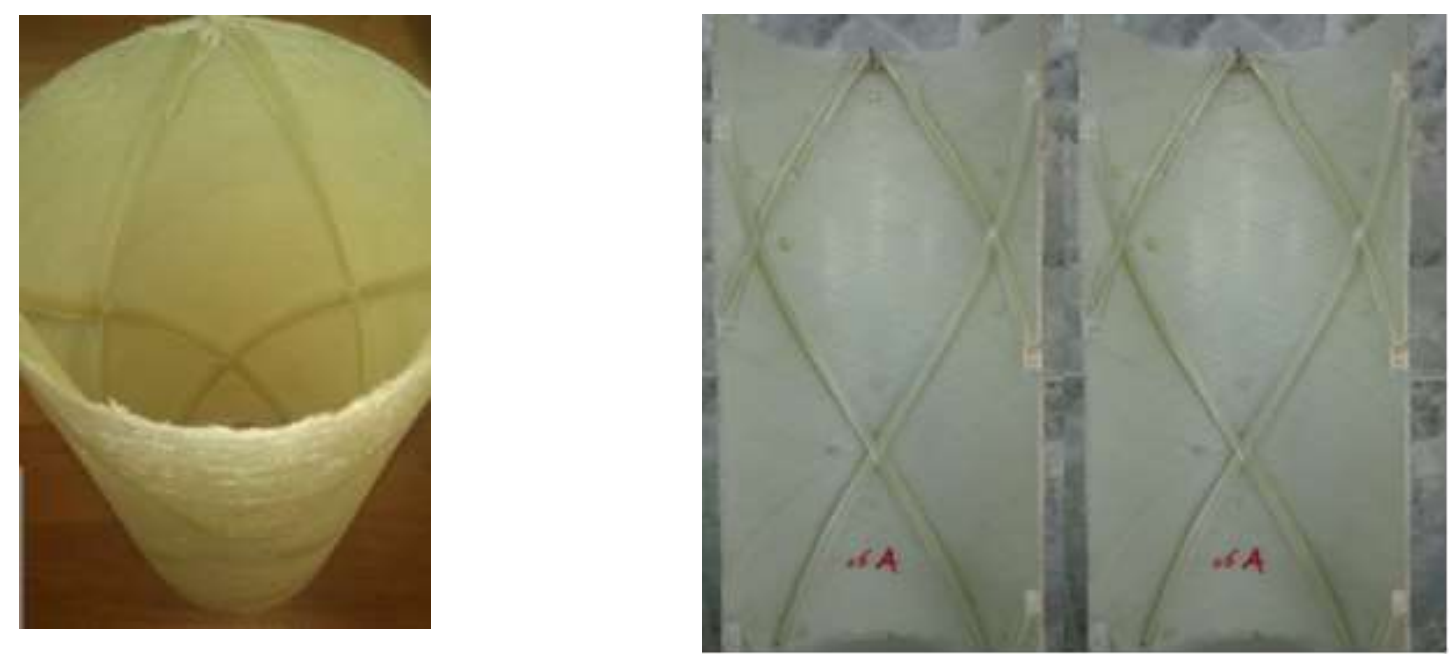

Figure 3: (a) A specimen manufactured by filament winding machine. (b) The specimen divided in two halves.

\section{Results and Discussion}

\subsection{Residual velocity}

Initially the center of each cell was chosen as position of collision. In this situation the initial and the residual velocities of ballistic impact were recorded at $139 \mathrm{~m} / \mathrm{s}$ and $107 \mathrm{~m} / \mathrm{s}$, respectively. This residual velocity is exactly the same magnitude as that measured from tests on unstiffened composite shell. Therefore for this case, due to the large size of each cell and the local effects of ballistic impact, the presence of reinforcements (ribs) would not affect the exit velocity of the projectile.

In the next step, for analyzing the ribs effects on the exit velocity, the position of projectile collision was changed. For impacting near ribs intersection $(5.5 \mathrm{~cm})$, a velocity of $119 \mathrm{~m} / \mathrm{s}$ was recorded as exit velocity of projectile when the initial velocity was $140 \mathrm{~m} / \mathrm{s}$. 
This is due to the fact that due to presence of ribs, stiffness within each cell is not uniform, getting closer to the ribs location, stiffness increases locally. Therefore, position of impact is considered as one of the parameters affecting the exit velocity of projectile.

Local and global deformations are two main energy absorbing mechanisms of composite structures subjected to impact loading.

- Global deformation: ribs in grid structures are treated as an elastic foundation which decreases deflection and global deformation of the structure.

- Local deformation: in the next section we will show that existence of ribs lead to decrease in the damaged area.

The experimental data of incident impact velocity and exit velocities, deviation angle and damaged area in velocities higher than ballistic limit are summarized in Table 2.

Table 2: Impact results at velocity higher than ballistic limit

\begin{tabular}{c|c|c|c|c}
\hline Impact position & $\begin{array}{c}\text { Incident impact } \\
\text { velocity of } \\
\text { projectile }(\mathrm{m} / \mathrm{s})\end{array}$ & $\begin{array}{c}\text { Exit velocity } \\
\text { of projectile } \\
(\mathrm{m} / \mathrm{s})\end{array}$ & $\begin{array}{c}\text { Deviation angle } \\
\text { of projectile }(\mathrm{deg})\end{array}$ & $\begin{array}{c}\text { Damaged } \\
\text { area }\left(\mathrm{cm}^{2}\right)\end{array}$ \\
\hline Unstiffened shell & 139 & 106 & 0 & - \\
Center of cell & 139 & 106 & 0 & 13.75 \\
Center of cell & 139 & 21 & 45 & 34.96 \\
Center of cell & 139 & 48 & 30 & 19.28 \\
$\begin{array}{c}\text { Near ribs } \\
\text { intersection }\end{array}$ & 138 & 119 & 0 & 10.74 \\
$\begin{array}{c}\text { Near ribs } \\
\text { intersection }\end{array}$ & 140 & 117 & 10 & 11.52 \\
\hline
\end{tabular}

As can be seen from Table 2 for velocity higher than ballistic limit, the ribs effect on decreasing damaged area and global deflections is more significant than the effect caused by increasing stiffness. Thus, by getting close to the ribs location; the exit velocity of 
projectile has been increased. Table 3 reveals that in near ballistic limit, grid structure behaves differently.

Table 3: results in velocity near ballistic limit

\begin{tabular}{c|c|c|c}
\hline Impact position & $\begin{array}{c}\text { Incident impact } \\
\text { velocity of } \\
\text { projectile }(\mathrm{m} / \mathrm{s})\end{array}$ & $\begin{array}{c}\text { Exit velocity of } \\
\text { projectile }(\mathrm{m} / \mathrm{s})\end{array}$ & $\begin{array}{c}\text { Damaged area } \\
\left(\mathrm{cm}^{2}\right)\end{array}$ \\
\hline Near ribs intersection $(5.5 \mathrm{~cm})$ & 104 & 0 & 15.84 \\
Center of cell & 104 & 74 & 11.32 \\
\hline
\end{tabular}

The structure has not perforated by projectile with an initial velocity of $104 \mathrm{~m} / \mathrm{s}$ which has collided near ribs intersection whereas another projectile which has collided at the center of one cell with this velocity has been exited from the structure with velocity of $74 \mathrm{~m} / \mathrm{s}$. It means in velocities near ballistic limit, the ribs effect on increasing stiffness is more effective than decreasing damaged area and global deflections so in this case by getting closer to the ribs location, the structure absorbs more energy of the projectile.

\subsection{Damaged area}

One of the most important properties that makes difference between unstiffened composite shells and grid stiffened composite shells is damaged area.

For any impact situations, increased damaged area results in a higher energy absorption that leads to a decrease of the exit velocity of the projectile. Investigating all the specimens after ballistic tests performed showed that damaged area is increased just until the ribs location (Figure 4). In fact, existence of discrete ribs prevents pervading of damaged area of one cell 
to its adjacent cells (damage arrester). This property increases failure resistance of these structures.

As shown in Table 2 and Figure 5, when damaged area increased, the exit velocity of projectile is decreased subsequently.
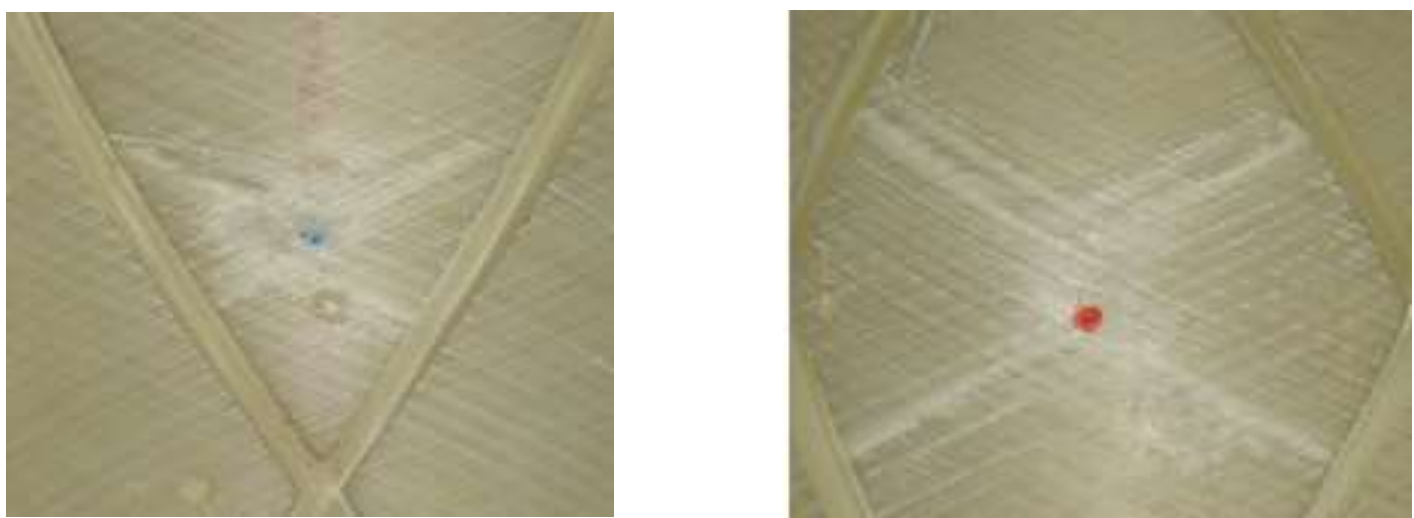

Figure 4: Pervading of damaged areas. The red and blue circles show the location of projectiles impact.

For example, for a sample with $35 \pm 0.05 \mathrm{~cm}^{2}$ damaged area, $21 \mathrm{~m} / \mathrm{s}$ was recorded as the exit velocity of projectile. As shown in Figure 5, with decreasing the damaged area up to $13.75 \pm 0.05 \mathrm{~cm}^{2}$, the exit velocity is increased up to $106 \mathrm{~m} / \mathrm{s}$.

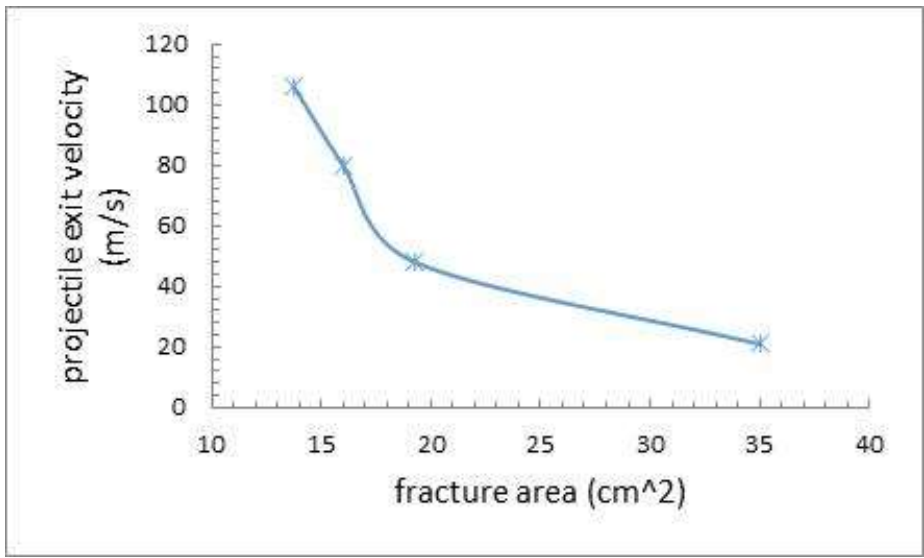

Figure 5: Damaged area and residual velocity of projectile. 
Damaged areas are depicted in Figure 6 for two different specimens. Scanned images and dimensional scale module of AutoCAD software was used for calculating the damaged areas.
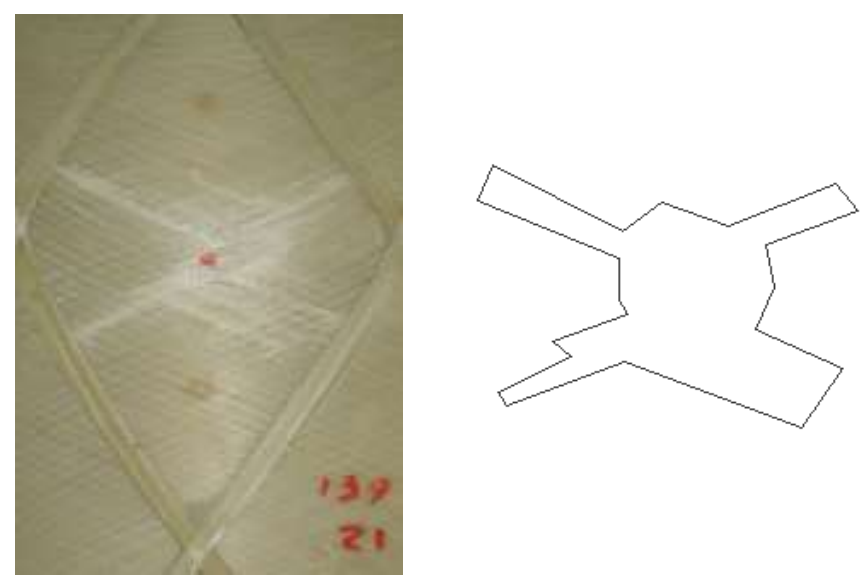

(a)
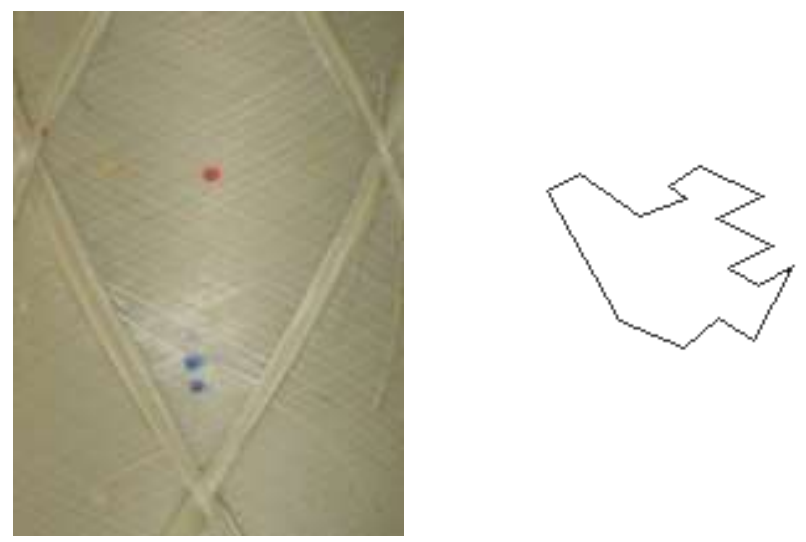

(b)

Figure 6: Representative damaged areas. In (a) red circle and in (b) the upper blue circle shows the location of projectiles impact. 


\subsection{Effect of Curvature}

The experimental results demonstrated that the curvature of the shell causes a deviation angle of projectile after impact and increasing deviation angle leads to a lower exit velocity of projectile.

In fact, a curved structure diverts collided projectiles and also, by increasing damaged area, the energy absorbed from the projectile increases. This is why curved structures are used widely in bumpers, armors and ship buildings. As shown in Figure 7 in specimens subjected to projectile impact with $139 \mathrm{~m} / \mathrm{s}$ initial velocity in which projectile was exited from the structure with no deviation, the average exit velocity of projectile is $106 \pm 3 \mathrm{~m} / \mathrm{s}$ and by increasing the deviation angle to 45 degree, the exit velocity is decreased to $21 \pm 5$ $\mathrm{m} / \mathrm{s}$.

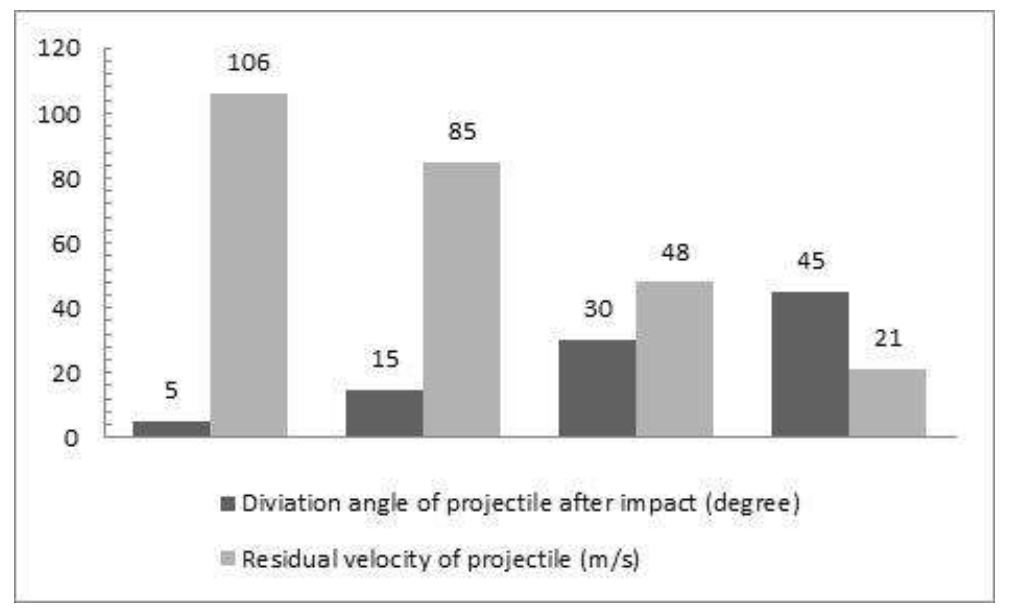

Figure 7: Residual velocity and deviation angle of projectile.

The relation between damaged area and deviation angle of projectile is another result that can be considered. As shown in Figure 8 increase in the deviation angle, caused an increment in damaged area. 


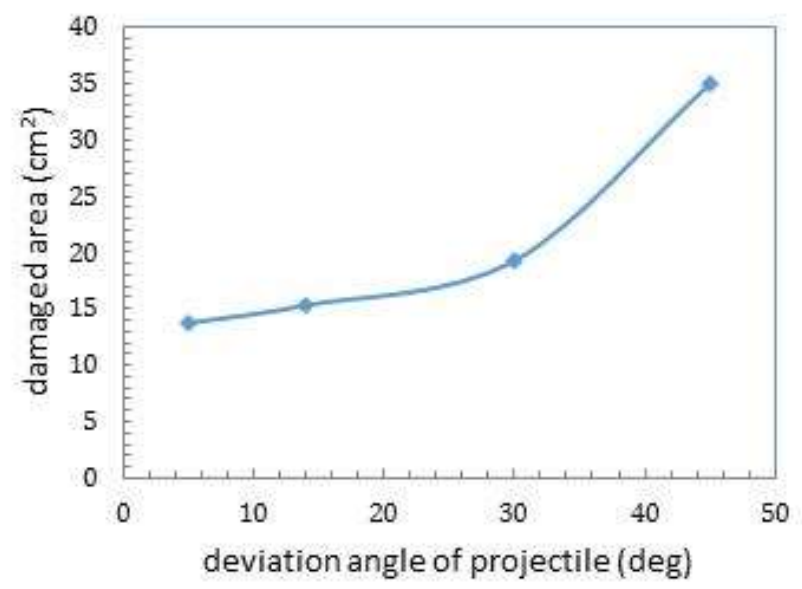

Figure 8: Damaged area versus deviation angle of projectile.

\subsection{Delamination}

\subsubsection{Delamination in composite shell}

Investigation of all the specimens after ballistic tests demonstrated that no delamination occurred in composite shell (for both of the velocities). Due to the lack of reinforcement in the thickness direction and, also, since interlaminar stresses exist in the boundary layer of laminates under transverse loading, the layers are likely to debond, and delamination is one of the prevailing forms of failure in laminated composites [29]. The results showed that in the mentioned structure due to low thickness of shell $(2.4 \mathrm{~mm})$ and numerous layers (15 layers), stresses do not exceed of allowable amounts and delamination phenomenon does not take place.

\subsubsection{Delamination in ribs}

Based on the experimental observations, none of the composites damage mechanisms occurred in the ribs. In the fabricating process, all the ribs were produced integrated by 
unidirectional fibers which were inserted in ribs direction. By using this procedure the highest volume percentage of fibers can be used.

\subsubsection{Separation of ribs and shell}

No separation of ribs and shell were took place in tested specimens. Depending on the applications of grid stiffened composite structures, different types of loading conditions such as buckling, twisting, low and high impact loading will be experienced by the structures during their usage. Because the shell is thin, the major part of loads is tolerated by the ribs. As a result, separation of ribs and shell will have catastrophic consequences. By employing this fabrication method (in this method ribs and shell are fabricated completely integrated), no separation of ribs and shell occurred in ballistic impact tests.

\section{Conclusion}

The main goal of this study was to investigate experimentally the behavior of cylindrical grid composite structures subjected to high velocity impact. It was shown that in grid composite structures subjected to impact, discrete ribs prevent pervading of damaged area of one cell to its adjacent cells. Therefore, when the skin is perforated in collision with tiny objects, shell damage does not lead to failure of the structure which its strength is controlled by the helical ribs.

In the tested specimens no debonding of ribs from the shell, or delamination in the ribs and shell were observed.

Therefore, using ribs in the grid composite structures that are subjected to impact loading have some important advantages such as increasing the stiffness of structure locally near the ribs, decreasing the local and global deformations of structure and confining damaged area to one cell. In velocity higher than ballistic limit, the ribs effect on decreasing 
damaged area and global deflections is more significant than increasing stiffness and in velocities near ballistic limit; the ribs effect on increasing stiffness is more effective than decreasing damaged area and global deflections. 


\section{References}

[1] Y.W. Kim, J. Sound. Vibrat., pp. 1-17, 2002.

[2] F. Léné, G. Duvaut, Compos. Struct., pp. 392-397, 2009.

[3] D. Poorveis, Scientia Iranica., pp.113-123, 2006.

[4] V. V. Vasiliev and A. F. Razin, Compos. Struct., vol. 76, no. 1, pp. 182-189, 2006.

[5] V. V. Vasiliev, V. A. Barynin, and A. F. Razin, Compos. Struct., vol. 94, no. 3, pp. 1117 1127, Feb. 2012.

[6] F. Dogan, H. Hadavinia, T. Donchev, P. S. Bhonge, Cent. Eur. J. Eng., vol. 2, no. 4, pp.612626, 2012.

[7] H. Ghasemnejad, H. Hadavinia, and A. Aboutorabi, Mater. Des., vol. 31, no. 3, pp. 11051116, 2010.

[8] T. Mitrevski, I. H. H. Marshall, R. Thomson, R. Jones, and B. Whittingham, Compos. Struct., vol. 67, no. 2, pp. 139-148, Feb. 2005.

[9] W. J. Cantwell, P. T. Curtis, and J. Morton, Compos. Sci. Technol., vol. 25, no. 2, pp. 133$148,1986$.

[10] S. Abrate, Compos. Struct., vol. 51, no. 2, pp. 129-138, 2001.

[11] D. Varas, R. Zaera, and J. López-Puente, Compos. Struct., vol. 93, no. 10, pp. 2598-2609, 2011.

[12] C. Evci and M. Gülgeç, Int. J. Impact Eng., vol. 43, pp. 40-51, May 2012.

[13] G. Zhao and C. Cho, J. Compos. Mater., vol. 38, no. 14, pp. 1231-1254, 2004.

[14] G. Zhou, Compos. Struct., vol. 42, no. 4, pp. 375-382, 1998.

[15] K. S. Krishnamurthy, P. Mahajan, and R. K. Mittal, Compos. Struct., vol. 59, no. 1, pp. 1536, Jan. 2003.

[16] M. Mamivand and G. H. Liaghat, Int. J. Impact Eng., vol. 37, no. 7, pp. 806-812, Jul. 2010.

[17] H. Sabouri and G. H. Liaghat, Compos. Struct., vol. 92, no. 2, pp. 600-601, Jan. 2010.

[18] G. P. Zhao and C. D. Cho, Compos. Struct., vol. 78, no. 1, pp. 91-100, Mar. 2007.

[19] X. Zhang, Proc. Inst. Mech. Eng. Part G J. Aerosp. Eng., vol. 212, no. 4, pp. 245-259, 1998. 
[20] J. Pernas-Sánchez, J. A. Artero-Guerrero, J. Zahr Viñuela, D. Varas, and J. López-Puente, Compos. Struct., vol. 107, pp. 629-634, Jan. 2014.

[21] L. Jing, Z. Wang, and L. Zhao, Compos. Struct., vol. 107, pp. 36-47, Jan. 2014.

[22] W. J. Cantwell and J. Morton, Compos. Sci. Technol., vol. 38, no. 2, pp. 119-141, 1990.

[23] T.-W. Shyr and Y.-H. Pan, Compos. Struct., vol. 62, no. 2, pp. 193-203, Nov. 2003.

[24] A. H. Sheikh, P. H. Bull, and J. A. Kepler, Compos. Sci. Technol., vol. 69, no. 6, pp. 704710, 2009.

[25] R. Karakuzu, E. Erbil, and M. Aktas, Compos. Part B Eng., vol. 41, no. 5, pp. 388-395, Jul. 2010.

[26] S. Kidane, G. Li, J. Helms, S.-S. Pang, and E. Woldesenbet, Compos. Part B Eng., vol. 34, no. 1, pp. 1-9, 2003.

[27] M. Yazdani, H. Rahimi, A. A. Khatibi, and S. Hamzeh, Sci. Res. Essay, vol. 4, no. 9, pp. 914-920, 2009.

[28] G. H. Rahimi, M. Zandi, and S. F. Rasouli, Aerosp. Sci. Technol., vol. 24, no. 1, pp. 198203, Jan. 2013.

[29] k. Gordnian, H. Hadavinia, P.J. Mason, E. Madenci, Compos. Struct., vol. 82(4), pp. 577-586, 2008. 